\title{
Efficacy and Safety of Ceftaroline for the Treatment of Community-Acquired Pneumonia: A Systemic Review and Meta-Analysis of Randomized Controlled Trials
}

\author{
Shao-Huan Lan ${ }^{1}$, Shen-Peng Chang ${ }^{2}$, Chih-Cheng Lai ${ }^{3}{ }^{1}$, Li-Chin Lu ${ }^{4}$ and Chien-Ming Chao ${ }^{3, *}$ \\ 1 School of Pharmaceutical Sciences and Medical Technology, Putian University, Putian 351100, Fujian, China; \\ shawnlan0713@gmail.com \\ 2 Department of Pharmacy, Chi Mei Medical Center, Liouying 73657, Taiwan; httremoon@ms.szmc.edu.tw \\ 3 Department of Intensive Care Medicine, Chi Mei Medical Center, Liouying 73657, Taiwan; \\ dtmed141@gmail.com \\ 4 School of Management, Putian University, Putian 351100, Fujian, China; jane90467@gmail.com \\ * Correspondence: ccm870958@yahoo.com.tw
}

Received: 15 May 2019; Accepted: 7 June 2019; Published: 9 June 2019

check for updates

\begin{abstract}
This study aimed to compare the clinical efficacy and safety of ceftaroline with those of ceftriaxone for treating community-acquired pneumonia (CAP). The PubMed, Cochrane Library, Embase, and clinicalTrials.gov databases were searched until April 2019. This meta-analysis only included randomized controlled trials (RCTs) that evaluated ceftaroline and ceftriaxone for the treatment of CAP. The primary outcome was the clinical cure rate, and the secondary outcome was the risk of adverse events (AEs). Five RCTs were included. Overall, at the test of cure (TOC), the clinical cure rate of ceftaroline was superior to the rates of ceftriaxone for the treatment of CAP (modified intent-to-treat population (MITT) population, odds ratio (OR) 1.61, 95\% confidence interval (CI) $1.31-1.99, I^{2}=0 \%$; clinically evaluable (CE) population, OR 1.38, 95\% CI 1.07-1.78, $I^{2}=14 \%$ ). Similarly, the clinical cure rate of ceftaroline was superior to that of ceftriaxone at the end of therapy (EOT) (MITT population, OR 1.57, 95\% CI 1.16-2.11, $I^{2}=0 \%$; CE population, OR 1.64, 95\% CI 1.15-2.33, $\left.I^{2}=0 \%\right)$. For adult patients, the clinical cure rate of ceftaroline remained superior to that of ceftriaxone at TOC (MITT population, OR 1.66, 95\% CI 1.34-2.06, $I^{2}=0 \%$; CE population, OR 1.39, 95\% CI $1.08-1.80, I^{2}=30 \%$ ) and at EOT (MITT population, OR 1.64, 95\% CI 1.20-2.24, $I^{2}=0 \%$; CE population, OR $1.65,95 \%$ CI $1.15-2.36, I^{2}=0 \%$ ). Ceftaroline and ceftriaxone did not differ significantly in the risk of serious AEs, treatment-emergent AEs, and discontinuation of the study drug owing to an AE. In conclusion, the clinical efficacy of ceftaroline is similar to that of ceftriaxone for the treatment of CAP. Furthermore, this antibiotic is as tolerable as ceftriaxone.
\end{abstract}

Keywords: ceftaroline; ceftriaxone; community-acquired pneumonia; safety

\section{Introduction}

Community-acquired pneumonia (CAP) is a common acute bacterial infection among adults and children and has become a significant global health problem [1-4]. Moreover, severe CAP is associated with high morbidity and mortality, particularly when prompt and appropriate treatment is not provided [5,6]. However, the emergence of antibiotic resistance in this era-with the increase in resistant bacteria not treatable with existing antibiotics-and the lack of development of novel antibiotics has complicated the use of antibiotics unlike before [3,7]. In addition to the most common CAP pathogen-Streptococcus pneumoniae, less than $8 \%$ of CAP can be caused by the so-called PES 
pathogens-Pseudomonas aeruginosa, extended-spectrum $\beta$-lactamase producing Enterobacteriaceae, and methicillin-resistant Staphylococcus aureus (MRSA), especially in intensive care unit (ICU) $[8,9]$. Among PES, MRSA is the most frequently reported, and it requires the use of specific antimicrobial agents for the treatment of typical CAP [10]. Currently, the antibiotics recommended for treating CAP when MRSA infection is suspected are vancomycin, teicoplanin, and linezolid [11-13].

Ceftaroline is a new cephalosporin with broad-spectrum activity against many commonly encountered pathogens causing CAP, including S. pneumoniae, S. aureus, Moraxella catarrhalis, Haemophilus influenzae, and Klebsiella pneumonia [14-16]. Moreover, several investigations have demonstrated the substantial in vitro activity of ceftaroline against MRSA from various clinical specimens, including skin/soft tissue and respiratory tract [15,17-19]. Global surveillance revealed that compared to ceftriaxone, ceftaroline showed superior in vitro activity against common CAP pathogens [17]. Subsequently, several randomized controlled trials (RCTs) [20-24] have investigated the efficacy and safety of ceftaroline for the treatment of CAP. In the present study, we conducted a comprehensive meta-analysis to provide high-quality evidence on the efficacy and safety of ceftaroline compared to those of ceftriaxone for treating CAP.

\section{Methods}

\subsection{Study Search and Selection}

All clinical studies were identified through a systematic review of the literature in the PubMed, Embase, ClinicalTrials.gov, and Cochrane databases until April 2019 using the following search terms: "ceftaroline", "Teflaro", "Zinforo", "pneumonia", and "RCT". Only RCTs that compared the clinical efficacy and adverse effects of ceftaroline and ceftriaxone were included. Two reviewers (Lan and Chang) searched and examined publications independently to avoid bias. When they disagreed, a third author (Lai) resolved the issue. The following data were extracted from each study included in the meta-analysis: year of publication, study design, duration, antibiotic regimens of ceftaroline and ceftriaxone, outcomes, and adverse events (AEs).

\subsection{Definitions and Outcomes}

The primary outcome was the overall clinical cure with the resolution of clinical signs and symptoms of pneumonia or improvement to the extent that no further antimicrobial therapy was necessary at the end of therapy (EOT) and test of cure (TOC) in the modified intent-to-treat population (MITT) and the clinically evaluable (CE) population. The EOT visit took place within $48 \mathrm{~h}$ after the last dose of oral study drug or within $24 \mathrm{~h}$ after the last dose of the IV study drug. The TOC visit was at 8-15 days after the last dose of the IV or oral study drug (whichever was given last). Patients in the MITT population who met minimal disease criteria and had $\geq 1$ bacterial pathogen commonly associated with CAP identified at baseline were included in the microbiological modified MITT (mMITT) population, and those who met criteria for both the CE and mMITT populations were included in the microbiologically evaluable (ME) population. The secondary outcome was the risk of AEs, including mild, moderate, and severe degree and discontinuation because of AEs, relapse rate, and mortality.

\subsection{Data Analysis}

This study used the Cochrane risk-of-bias tool to assess the quality of enrolled RCTs and their risk of bias [25]. The Review Manager software program, version 5.3, was used to conduct statistical analyses. The degree of heterogeneity was evaluated using the $Q$ statistic generated from the $\chi^{2}$ test. The $I^{2}$ measure assessed the proportion of statistical heterogeneity. Heterogeneity was considered significant when the $P$ value was less than 0.10 or the $I^{2}$ value was more than $50 \%$. The random-effects model was used when data were significantly heterogeneous, and the fixed-effect model was used 
when the data were homogeneous. Pooled odds ratios (ORs) and 95\% confidence intervals (CI) were calculated for outcome analyses.

\section{Results}

The search results yielded a total of 133 studies from the online databases, and 76 studies were excluded because of duplication. Additionally, 64 studies were found to be irrelevant after the title and abstract were screened (article type and language), and 7 studies were found to be irrelevant after the full text was screened. Eventually, five RCTs [20-24] were enrolled for the meta-analysis (Figure 1).



Figure 1. Flowchart of the study selection process.

\subsection{Study Characteristics and Study Quality}

All five RCTs [20-24] included were multinational and multicenter studies (Table 1). Three studies [20-22] focused on adult patients with CAP with Pneumonia Outcomes Research Term (PORT) [26] risk class III-IV, and two studies [23,24] enrolled pediatric patients only. Overall, the experimental group treated with ceftaroline and the control group treated with ceftriaxone comprised 1153 and 1050 patients, respectively. Almost all risks of basis in each study were low (Figure 2).

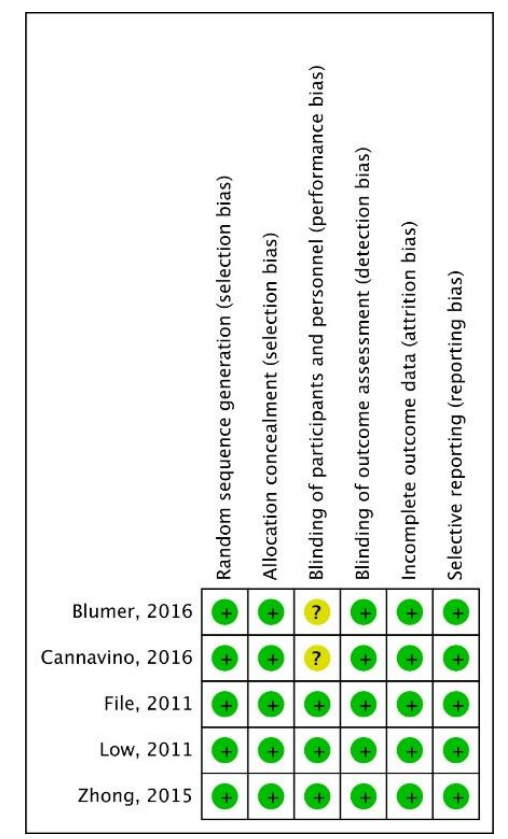

Figure 2. Risk of bias per study and domain. 
Table 1. Characteristics of included studies.

\begin{tabular}{|c|c|c|c|c|c|c|c|}
\hline \multirow{2}{*}{ Study, Published Year } & \multirow{2}{*}{ Study Design } & \multirow{2}{*}{ Study Period } & \multirow{2}{*}{ Study Population } & \multicolumn{2}{|c|}{ No of Patients } & \multicolumn{2}{|c|}{ Dose Regimen } \\
\hline & & & & Ceftaroline & Comparator & Ceftaroline & Comparator \\
\hline File et al., 2011 [20] & $\begin{array}{l}\text { Multicenter, multinational, } \\
\text { double-blinded, } \\
\text { randomized trial }\end{array}$ & $\begin{array}{l}\text { January } 2008 \text { to } \\
\text { December } 2008\end{array}$ & $\begin{array}{l}\text { Adult patients with PORT risk class III or IV } \\
\text { CAP requiring hospitalization and IV therapy }\end{array}$ & 304 & 309 & $600 \mathrm{mg} \mathrm{q} 12 \mathrm{~h}$ & Ceftriaxone $1 \mathrm{~g} \mathrm{q} 24 \mathrm{~h}$ \\
\hline Low et al., 2011 [21] & $\begin{array}{l}\text { Multicenter, multinational, } \\
\text { double-blinded, } \\
\text { randomized trial }\end{array}$ & 2007-2009 & $\begin{array}{l}\text { Patients (aged } \geq 18 \text { years) with PORT risk class } \\
\text { III or IV CAP requiring hospitalization and IV } \\
\text { therapy }\end{array}$ & 317 & 310 & $600 \mathrm{mg} \mathrm{q} 12 \mathrm{~h}$ & Ceftriaxone $1 \mathrm{~g} \mathrm{q} 24 \mathrm{~h}$ \\
\hline Zhong et al., 2015 [22] & $\begin{array}{l}\text { Multicenter, multinational, } \\
\text { double-blinded, } \\
\text { randomized trial }\end{array}$ & 2011-2013 & $\begin{array}{l}\text { Adult Asian patients with PORT risk class } \\
\text { III-IV CAP }\end{array}$ & 381 & 382 & $600 \mathrm{mg} \mathrm{q} 12 \mathrm{~h}$ & Ceftriaxone $2 \mathrm{~g} \mathrm{q} 24 \mathrm{~h}$ \\
\hline Cannavino et al., 2016 [23] & $\begin{array}{l}\text { Multicenter, multinational, } \\
\text { randomized }\end{array}$ & 2012-2014 & $\begin{array}{c}\text { Ages of } 2 \text { months and }<18 \text { years with CAP } \\
\text { requiring hospitalization and IV antibacterial } \\
\text { therapy }\end{array}$ & 121 & 39 & $\begin{array}{c}\text { Age }<6 \mathrm{~m}, 8 \mathrm{mg} / \mathrm{kg} \mathrm{q} 8 \mathrm{~h} \text {; aged } \geq 6 \mathrm{~m}, 12 \\
\mathrm{mg} / \mathrm{kg} \text { q } 8 \text { hor those weighing } \leq 33 \mathrm{~kg} \text { or } \\
400 \mathrm{mg} \mathrm{q} 8 \mathrm{~h} \text { for those weighing }>33 \mathrm{~kg}\end{array}$ & $\begin{array}{l}\text { Ceftriaxone } 75 \mathrm{mg} / \mathrm{kg} / \mathrm{d} \text { to a } \\
\text { maximum } 4 \mathrm{~g} / \mathrm{d} \text { q12 h }\end{array}$ \\
\hline Blumer et al., 2016 [24] & $\begin{array}{l}\text { Multicenter, multinational } \\
\text { randomized, } \\
\text { observe-blinded }\end{array}$ & 2012-2014 & $\begin{array}{l}\text { Pediatric patients between } 2 \text { months and } 17 \\
\text { years of age with complicated CAP }\end{array}$ & 30 & 10 & $\begin{array}{l}15 \mathrm{mg} / \mathrm{kg} \text { or } 600 \mathrm{mg} \mathrm{q} 8 \mathrm{~h} \text { if weight }>40 \\
\mathrm{~kg} \text { if } \geq 6 \mathrm{~m} \text { or } 10 \mathrm{mg} / \mathrm{kg} \mathrm{q} 8 \mathrm{~h} \text { if }<6 \mathrm{~m}\end{array}$ & $\begin{array}{c}\text { Ceftriaxone, } 75 \mathrm{mg} / \mathrm{kg} / \mathrm{d} \mathrm{q} 12 \\
\mathrm{~h} \text {, and vancomycin } 15 \\
\mathrm{mg} / \mathrm{kg} \mathrm{q} 6 \mathrm{~h}\end{array}$ \\
\hline
\end{tabular}




\subsection{Clinical Efficacy}

Notably, ceftaroline had a superior clinical cure rate at TOC compared with ceftriaxone for the treatment of CAP (MITT population, OR 1.61, 95\% CI 1.31-1.99, $I^{2}=0 \%$; CE population, OR 1.38, 95\% CI 1.07-1.78, $I^{2}=14 \%$; ME population, OR 1.98, 95\% CI 1.20-3.25, $I^{2}=0 \%$; Figure 3). Similarly, at EOT, the clinical cure rate of ceftaroline was superior compared with that of ceftriaxone (MITT population, OR 1.57, 95\% CI 1.16-2.11, $I^{2}=0 \%$; CE population, OR 1.64, 95\% CI 1.15-2.33, $I^{2}=0 \%$ ).

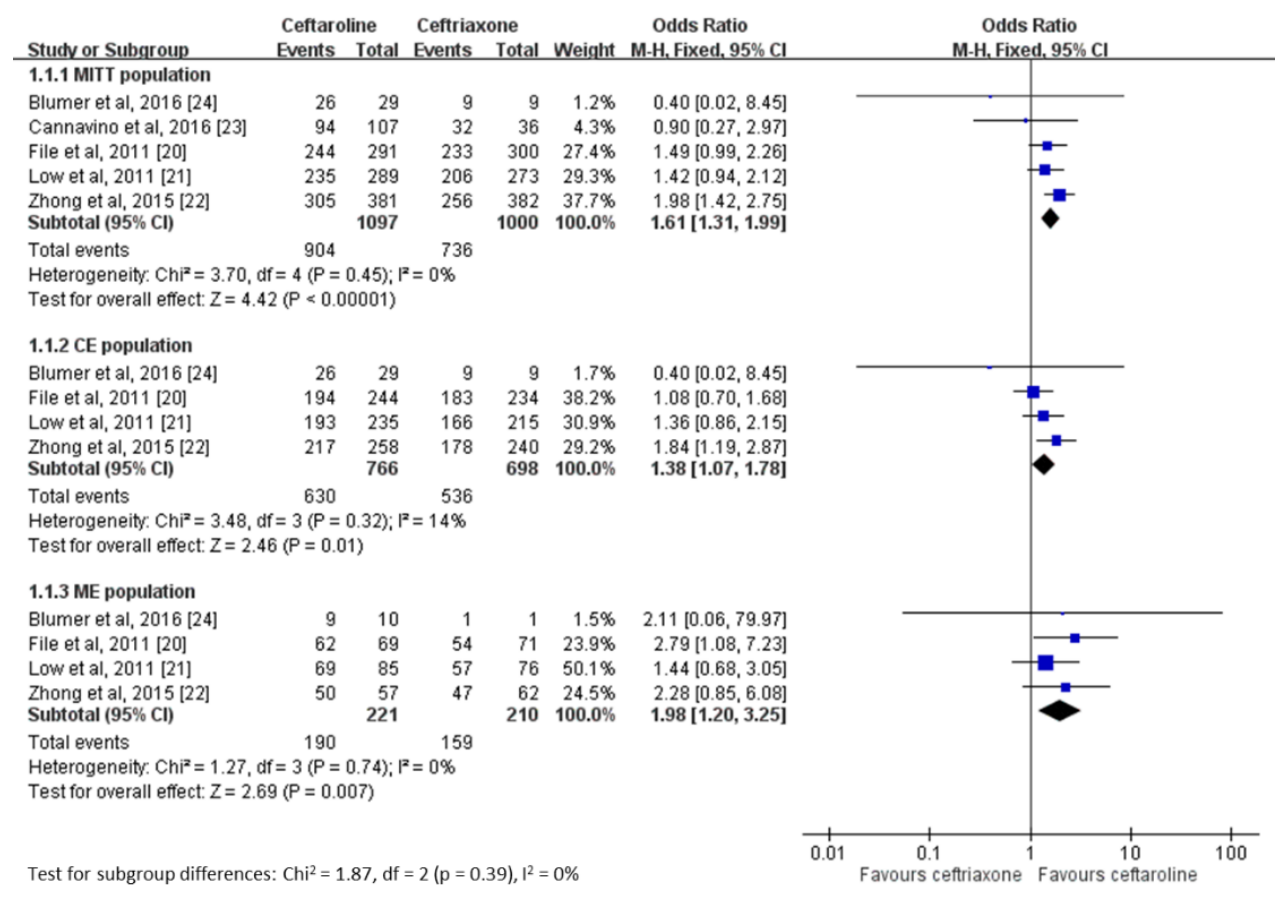

Figure 3. Overall clinical cure rates of ceftaroline and ceftriaxone for the treatment of communityacquired pneumonia. MITT, modified intent-to-treat population; CE, clinically evaluable; ME, microbiologically evaluable.

In the subgroup analysis of three studies [20-22] including adult patients, the clinical cure rate of ceftaroline remained superior to that of ceftriaxone at TOC (MITT population, OR $1.66,95 \%$ CI 1.34-2.06, $I^{2}=0 \%$; CE population, OR 1.39, 95\% CI 1.08-1.80, $I^{2}=30 \%$ ) and at EOT (MITT population, OR 1.64, 95\% CI 1.20-2.24, $I^{2}=0 \%$; CE population, OR 1.65, 95\% CI 1.15-2.36, $I^{2}=0 \%$ ). On the other hand, the pooled analysis of two studies showed that the clinical cure rates at TOC and EOT were similar between pediatric patients treated with ceftaroline or ceftriaxone (at TOC, OR $0.79,95 \%$ CI $0.26-2.97, I^{2}=0 \%$; at EOT, OR $1.02,95 \%$ CI $\left.0.38-2.75, I^{2}=0 \%\right)[23,24]$.

Figure 4 shows further analysis of the clinical cure rate (ceftaroline vs. ceftriaxone) at the TOC visit in various patient subgroups. Ceftaroline showed a superior clinical cure rate than ceftriaxone for patients with PORT risk III (OR 1.83, 95\% CI 1.26-2.67, $I^{2}=14 \%$ ) but not for patients with PORT risk IV (OR 1.39, 95\% CI 0.91-2.12, $I^{2}=0 \%$ ). The efficacy of ceftaroline was superior compared to that of ceftriaxone in patients who did not receive prior antibiotics (OR 1.90, 95\% CI 1.22-2.95, $I^{2}=37 \%$ ) but not in those who received prior antibiotics (OR 1.18, 95\% CI 0.75-1.87, $I^{2}=0 \%$ ). No differences were observed in the clinical cure rate between elderly patients (age $\geq 65$ years) treated with ceftaroline or ceftriaxone (OR 1.72, 95\% CI 0.95-3.11, $I^{2}=58 \%$ ) and between patients with bacteremia treated with ceftaroline or ceftriaxone (OR 1.62, 95\% CI 0.46-5.72, $I^{2}=0 \%$ ).

We also assessed the clinical cure rate based on pathogens among the mMITT population, and we found that ceftaroline was superior to ceftriaxone in the overall population (OR 1.94, 95\% CI 1.25-3.01, $I^{2}=0 \%$, Figure 5). Ceftaroline was superior to ceftriaxone in patients with gram-positive coccal (GPC) infection (OR 2.65, 95\% CI 1.40-5.01, $I^{2}=0 \%$ ) but not in those with gram-negative bacterial 
(GNB) infection (OR 1.26, 95\% CI 0.65-2.42, $I^{2}=0 \%$ ). No significant difference was noted between the ceftaroline and ceftriaxone groups for each of the following pathogens: S. pneumoniae, S. aureus, H. influenzae, H. parainfluenzae, Escherichia coli, and K. pneumoniae.

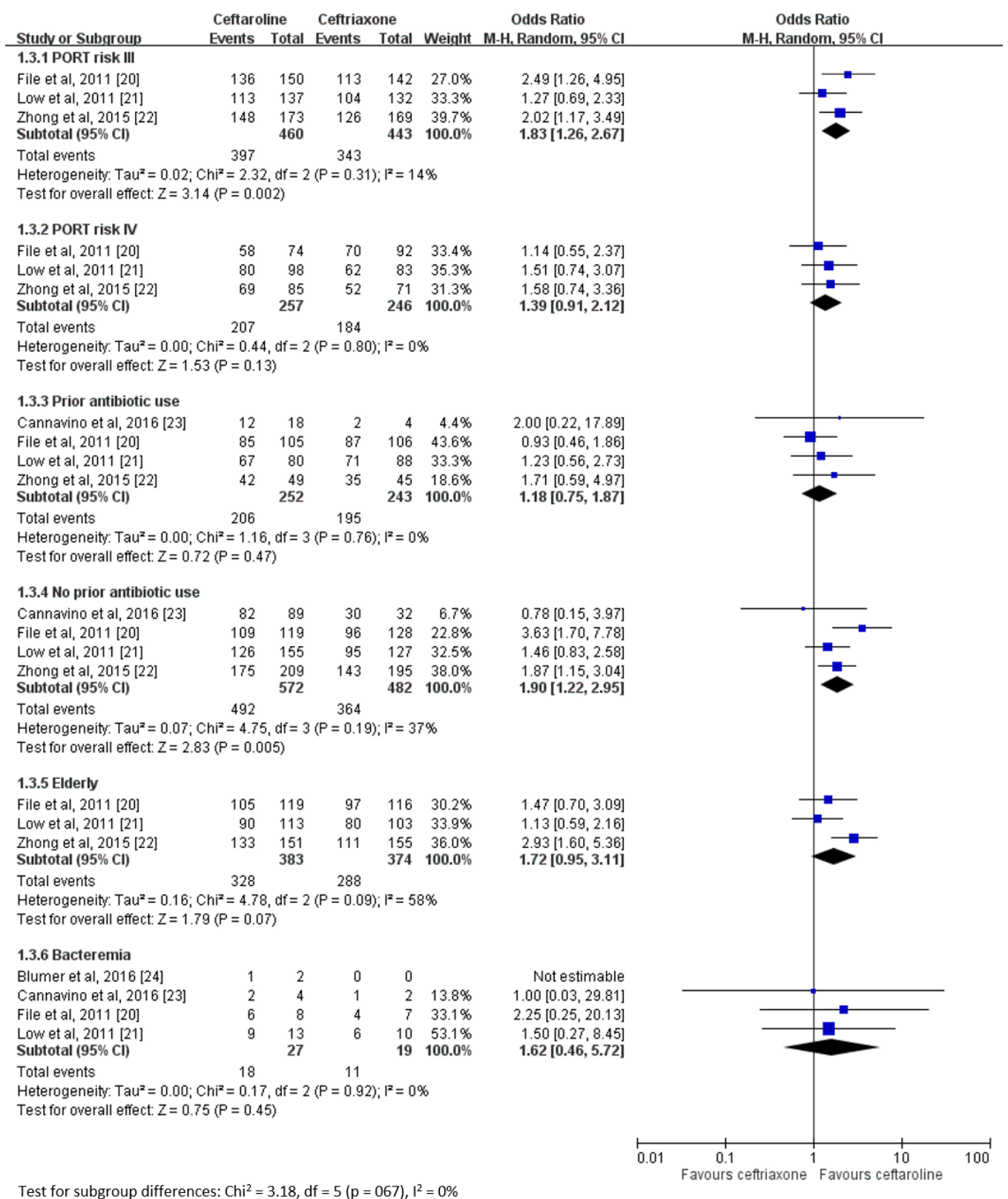

Figure 4. Overall clinical cure rates of ceftaroline and ceftriaxone for the treatment of communityacquired pneumonia based on patient group.

\subsection{Adverse Events}

No significant differences were observed in the risk of overall treatment-emergent adverse events (TEAEs) between the ceftaroline and ceftriaxone groups (OR 0.99, 95\% CI 0.75-1.30, $I^{2}=43 \%$ ), and the similarity was not changed by the degree of severity (Figure 6). The risks of serious AEs and discontinuation of the study drug were similar between the ceftaroline and ceftriaxone groups (Figure 5). In addition, no relapse was noted among all enrolled patients. Finally, the mortality rate was similar between the ceftaroline and ceftriaxone groups (OR $1.13,95 \% \mathrm{CI} 0.57-2.23, I^{2}=0$ ), and none of the cases of mortality were related to the study drug. 


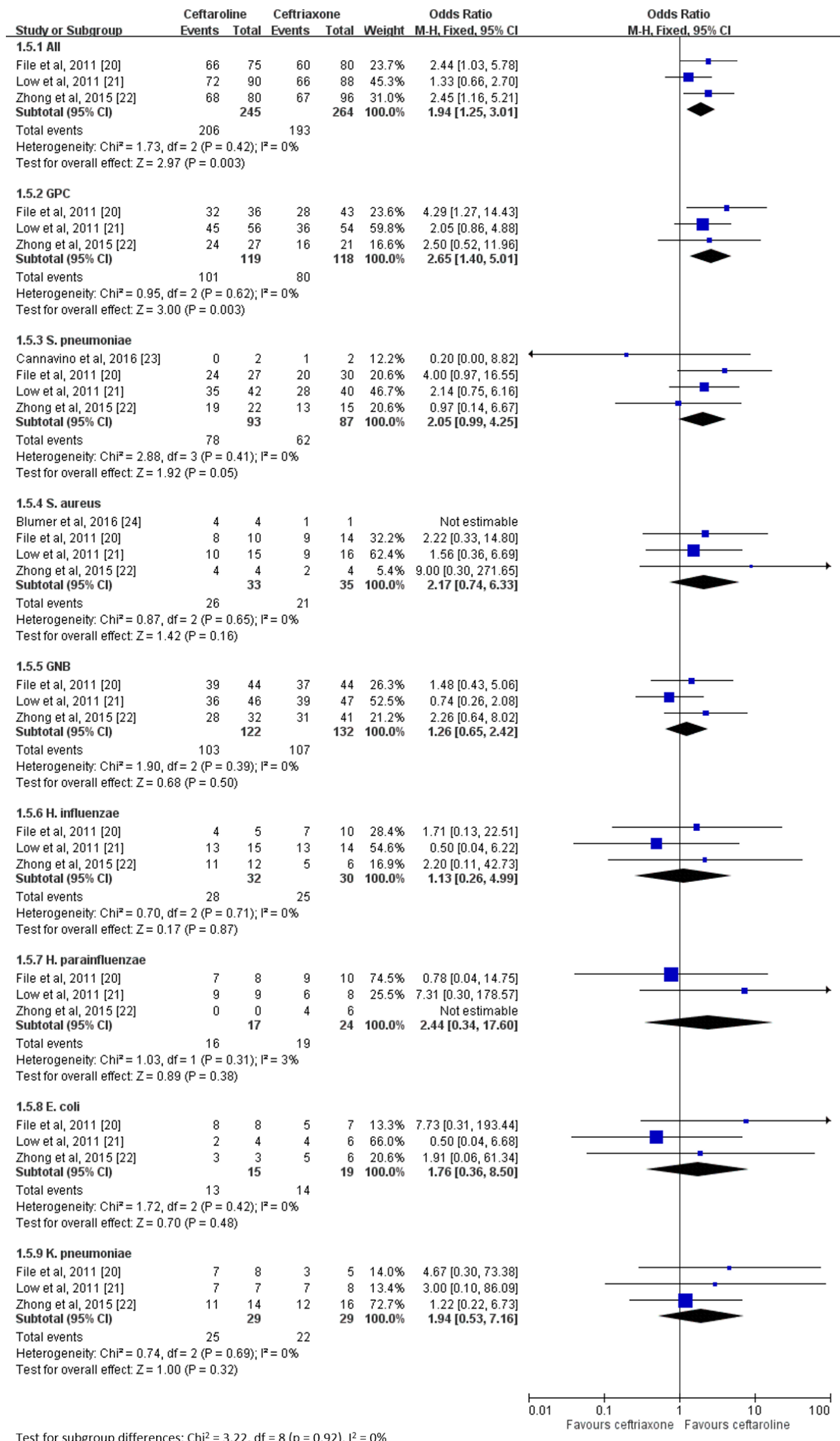

Figure 5. Overall clinical cure rates of ceftaroline and ceftriaxone for the treatment of communityacquired pneumonia based on pathogens. 


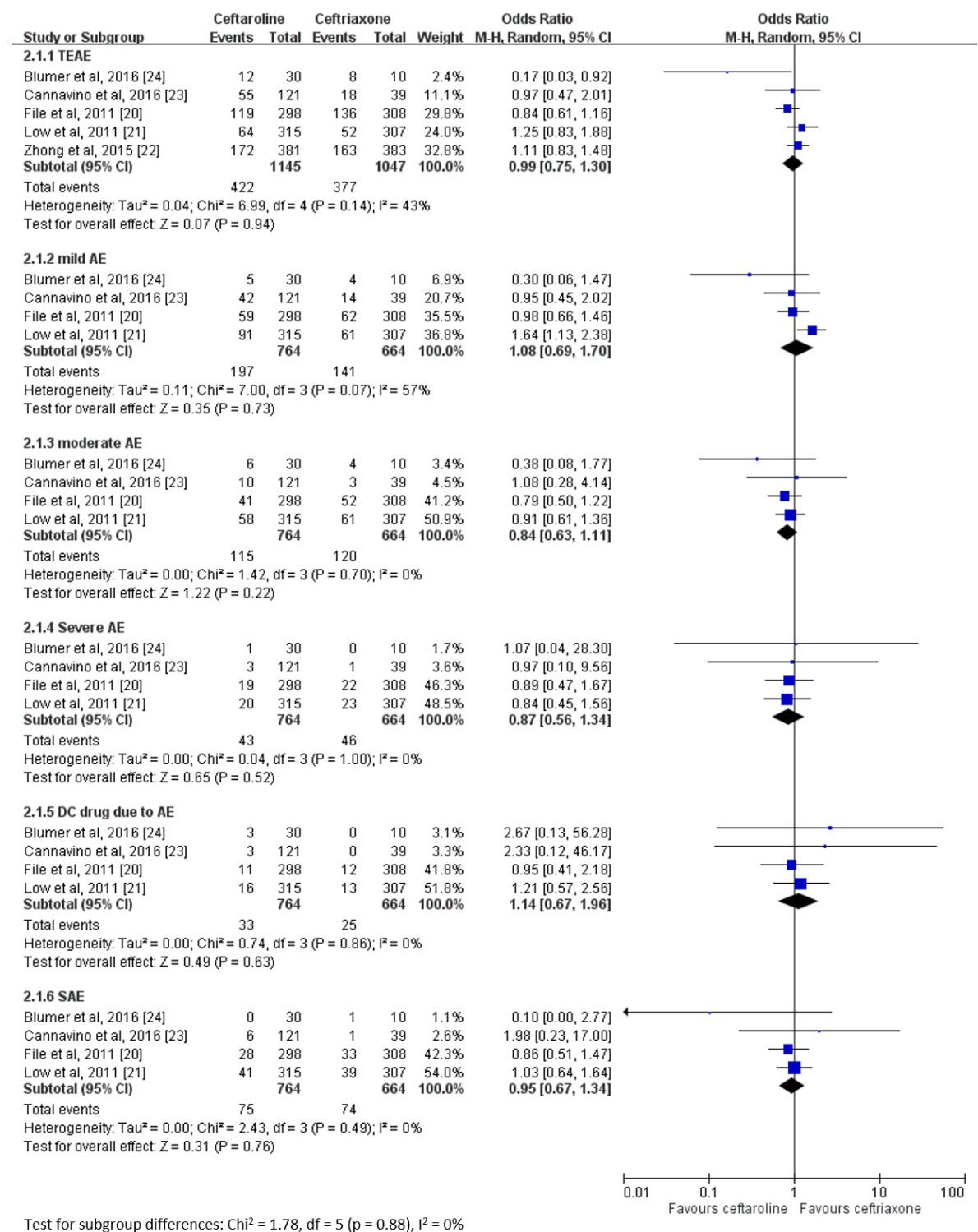

Figure 6. Risk of adverse events between ceftaroline and ceftriaxone for the treatment of communityacquired pneumonia.

\section{Discussion}

This meta-analysis of five RCTs determined that the clinical efficacy of ceftaroline was superior to that of ceftriaxone for the treatment of patients with CAP. First, the overall clinical cure rate of ceftaroline was superior to that of ceftriaxone for treating CAP in the pooled populations of the five RCTs, including pediatric and adult patients [20-24]. The superiority of ceftaroline compared to ceftriaxone remained significant at different times of outcome measurement, including EOT and TOC, and in different populations, including MITT, CE, and ME populations. Second, we found that ceftaroline had a higher clinical cure rate than ceftriaxone among adult patients in the subgroup analysis of three studies [20-22] including adult patients, but the pooled analysis of two studies [23,24] including pediatric patients showed similar clinical cure rates for ceftaroline and ceftriaxone. However, the two studies $[23,24]$ that focused on pediatric patients had a limited number of patients. Therefore, more pediatric studies are warranted to clarify this issue. Third, the subgroup analysis of CAP in various populations demonstrated that ceftaroline was at least similar to ceftriaxone in patients with PORT risk IV, those who received previous antibiotics, those who were aged $\geq 65$ years, and those with bacteremia but superior to ceftriaxone in patients with PORT risk III and those who did not 
receive previous antibiotics. In summary, the overall clinical efficacy of ceftaroline is similar to that of ceftriaxone for the treatment of CAP. For other populations, ceftaroline is at least similar to ceftriaxone in terms of the clinical cure rate. However, the case numbers of several subgroup analyses, such as bacteremia, PORT risk IV or different pathogens were limited, which may limit the significance of differences between ceftaroline and ceftriaxone. Therefore, a further large-scale study is warranted to prove our findings.

In the mMITT population, the present meta-analysis determined that the clinical cure rate of ceftaroline was superior to that of ceftriaxone for CAP caused by GPC, but no significant difference was found for CAP caused by GNB, S. pneumoniae, S. aureus, H. influenzae, H. parainfluenzae, E. coli, and K. pneumoniae between the ceftaroline and ceftriaxone groups. The effectiveness of ceftaroline for the treatment of CAP is supported by in vitro studies. In a surveillance study at a US medical center, ceftaroline was noted to be more potent against S. pneumoniae $\left(\mathrm{MIC}_{50} \leq 0.015 \mathrm{vs} . \leq 0.06 \mu \mathrm{g} / \mathrm{mL}\right.$; $\mathrm{MIC}_{90}=0.12$ vs. $1 \mu \mathrm{g} / \mathrm{mL}$ ) and even remained active against strains nonsusceptible to ceftriaxone $\left(\mathrm{MIC}_{90}=0.25 \mu \mathrm{g} / \mathrm{mL}\right)$ [18]. Similar findings were demonstrated in the analysis of bacterial isolates in pediatric patients [15]. Upon global surveillance, ceftaroline was noted to be more potent than ceftriaxone against MSSA and S. pneumoniae, and ceftaroline had similar efficacy to ceftriaxone against H. influenzae [17]. Overall, the in vitro activity of ceftaroline that is greater or at least equal to ceftriaxone against most commonly encountered pathogens causing CAP could largely explain the high in vivo clinical response in this meta-analysis. However, we can only see the trend of better efficacy of ceftaroline than the comparator in each subgroup; these differences do not reach statistical significance. This may be due to the limited case number of each pathogen, so further large-scale study is warranted.

Although this study demonstrated the clinical efficacy of ceftaroline in the treatment of CAP, antibiotics may have a limited effect on the outcome of CAP, particularly these severely affected cases. This could be due to the fact that pneumonia is caused by a variety of pathogens, including respiratory viruses, Mycoplasma pneumoniae, and bacteria. In addition, incidence of primary bacterial pneumonia may be very low and be far less than that of nonbacterial pneumonia in developed countries as well as in developing countries [27]. Incidences of each pathogen pneumonia may differ in children and adults (older persons) across the populations, but severe pneumonia of viral or nonpathogen origin can induce secondary bacterial infection caused by lung injuries from primary insults; hence, it is reasonable that any pneumonia patients could be treated with antibiotics. However, antibiotics have a limited effect on the natural course of infection-related extrapulmonary manifestations. Further, outcomes of severe pneumonia may be affected by underlying comorbidities or the immune status of the host, not only by antibiotic treatment. Moreover, the pattern of antimicrobial resistance may vary in different sites; therefore, the guidelines for antibiotic treatment for CAP may differ and could be changed in each country over time. In summary, although the appropriate use of antibiotics is essential for the successful treatment of pneumonia, many factors, including disease severity, underlying comorbidity, immune status, pathogens, and the timing of antibiotic use are also significantly associated with the outcome of pneumonia.

The risk of AEs is another major concern when treating CAP with this antimicrobial agent. The most common AEs are headache, diarrhea, and insomnia [28]. In this analysis, the pooled risks of TEAEs of all degrees and even serious AEs were similar between the ceftaroline and ceftriaxone groups. Additionally, ceftaroline is associated with the risk of discontinuation of the study drug that is similar to that of ceftriaxone; this risk is because of the development of AEs. Although the overall mortality of the ceftaroline group was only $1.81 \%$ - which was comparable to that of ceftriaxone group-none of the cases of mortality were associated with the study drug. Therefore, all these findings revealed that ceftaroline is as safe as ceftriaxone for the treatment of CAPs.

A major strength of this meta-analysis is that only RCTs were included, thereby reducing the risk of bias and providing strong evidence. However, this meta-analysis also has several limitations. First, the number of MRSA-associated pneumonia cases was limited in this study. Therefore, the anti-MRSA effect of ceftaroline, which is not owned by ceftriaxone, cannot be elucidated in this meta-analysis. 
Second, this meta-analysis had a limited number of studies and patients in subgroup analyses, such as different pathogens among different age groups. Therefore, some differences between the ceftaroline and ceftriaxone groups did not reach statistical significance.

\section{Conclusions}

In conclusion, based on the findings of this meta-analysis of five RCTs, the clinical efficacy of ceftaroline is similar to that of ceftriaxone for the treatment of CAP. Additionally, ceftaroline was as tolerable as ceftriaxone. However, clinicians should cautiously use ceftaroline in the selected population at high risk of MRSA to avoid the unnecessary coverage of MRSA by ceftaroline. Overall, ceftaroline can be recommended as an appropriate antibiotic therapy for CAP.

Author Contributions: Conceptualization, S.-H.L., S.-P.C., C.-C.L., C.-M.C.; methodology: S.-H.L., S.-P.C., L.-C.L.; writing—original draft preparation, C.-C.L., C.-M.C.; writing—review and editing, C.-M.C.

Conflicts of Interest: The authors declare no conflict of interest.

\section{References}

1. Le Roux, D.M.; Zar, H.J. Community-acquired pneumonia in children-A changing spectrum of disease. Pediatr. Radiol. 2017, 47, 1392-1398. [CrossRef] [PubMed]

2. Musher, D.M.; Thorner, A.R. Community-acquired pneumonia. N. Engl. J. Med. 2014, 37, 1619-1628. [CrossRef] [PubMed]

3. Peyrani, P.; Mandell, L.; Torres, A.; Tillotson, G.S. The burden of community-acquired bacterial pneumonia in the era of antibiotic resistance. Expert Rev. Respir. Med. 2019, 13, 139-152. [CrossRef] [PubMed]

4. Cilloniz, C.; Dominedo, C.; Garcia-Vidal, C.; Torres, A. Community-acquired pneumonia as an emergency condition. Curr. Opin. Crit. Care 2018, 24, 531-539. [CrossRef] [PubMed]

5. Leoni, D.; Rello, J. Severe community-acquired pneumonia: Optimal management. Curr. Opin. Infect. Dis. 2017, 30, 240-247. [CrossRef] [PubMed]

6. Pereira, J.M.; Goncalves-Pereira, J.; Ribeiro, O.; Baptista, J.P.; Froes, F.; Paiva, J.A. Impact of antibiotic therapy in severe community-acquired pneumonia: Data from the Infauci study. J. Crit. Care 2018, 43, $183-189$. [CrossRef] [PubMed]

7. Wunderink, R.G.; Yin, Y. Antibiotic Resistance in Community-Acquired Pneumonia Pathogens. Semin. Respir. Crit. Care Med. 2016, 37, 829-838.

8. Cilloniz, C.; Dominedo, C.; Nicolini, A.; Torres, A. PES Pathogens in Severe Community-Acquired Pneumonia. Microorganisms 2019, 7, 49. [CrossRef]

9. Torres, A.; Chalmers, J.D.; Dela Cruz, C.S.; Dominedo, C.; Kollef, M.; Martin-Loeches, I.; Niederman, M.; Wunderink, R.G. Challenges in severe community-acquired pneumonia: A point-of-view review. Intensiv. Care Med. 2019, 45, 159-171. [CrossRef]

10. Thomas, R.; Ferguson, J.; Coombs, G.; Gibson, P.G. Community-acquired methicillin-resistant Staphylococcus aureus pneumonia: A clinical audit. Respirology 2011, 16, 926-931. [CrossRef]

11. Chou, C.C.; Shen, C.F.; Chen, S.J.; Chen, H.M.; Wang, Y.C.; Chang, W.S.; Chang, Y.T.; Chen, W.Y.; Huang, C.Y.; Kuo, C.C.; et al. Recommendations and guidelines for the treatment of pneumonia in Taiwan. J. Microbiol. Immunol. Infect. 2019, 52, 172-199. [CrossRef] [PubMed]

12. Liu, C.; Bayer, A.; Cosgrove, S.E.; Daum, R.S.; Fridkin, S.K.; Gorwitz, R.J.; Kaplan, S.L.; Karchmer, A.W.; Levine, D.P.; Murray, B.E.; et al. Clinical practice guidelines by the infectious diseases society of America for the treatment of methicillin-resistant Staphylococcus aureus infections in adults and children. Clin. Infect. Dis. 2011, 52, e18-e55. [CrossRef] [PubMed]

13. Lim, W.S.; Baudouin, S.V.; George, R.C.; Hill, A.T.; Jamieson, C.; Le Jeune, I.; Macfarlane, J.T.; Read, R.C.; Roberts, H.J.; Levy, M.L.; et al. BTS guidelines for the management of community acquired pneumonia in adults: Update 2009. Thorax 2009, 64 (Suppl. 3), iii1-55. [CrossRef]

14. Pfaller, M.A.; Mendes, R.E.; Duncan, L.R.; Flamm, R.K.; Sader, H.S. In Vitro Activities of Ceftaroline and Comparators against Streptococcus pneumoniae Isolates from U.S. Hospitals: Results from Seven Years of the AWARE Surveillance Program (2010 to 2016). Antimicrob. Agents Chemother. 2018, 62, e01555-17. [CrossRef] [PubMed] 
15. Pfaller, M.A.; Mendes, R.E.; Castanheira, M.; Flamm, R.K.; Jones, R.N.; Sader, H.S. Ceftaroline Activity Tested Against Bacterial Isolates Causing Community-acquired Respiratory Tract Infections and Skin and Skin Structure Infections in Pediatric Patients From United States Hospitals: 2012-2014. Pediatr. Infect. Dis. J. 2017, 36, 486-491. [CrossRef]

16. Karlowsky, J.A.; Biedenbach, D.J.; Bouchillon, S.K.; Hackel, M.; Iaconis, J.P.; Sahm, D.F. In vitro activity of Ceftaroline against bacterial pathogens isolated from patients with skin and soft tissue and respiratory tract infections in African and Middle Eastern countries: AWARE global surveillance program 2012-2014. Diagn. Microbiol. Infect. Dis. 2016, 86, 194-199. [CrossRef]

17. Biedenbach, D.J.; Iaconis, J.P.; Sahm, D.F. Comparative in vitro activities of ceftaroline and ceftriaxone against bacterial pathogens associated with respiratory tract infections: Results from the AWARE surveillance study. J. Antimicrob. Chemother. 2016, 71, 3459-3464. [CrossRef]

18. Sader, H.S.; Farrell, D.J.; Mendes, R.E.; Flamm, R.K.; Castanheira, M.; Jones, R.N. Antimicrobial activity of ceftaroline tested against bacterial isolates causing respiratory tract and skin and skin structure infections in US medical centers in 2013. Diagn. Microbiol. Infect. Dis. 2015, 82, 78-84. [CrossRef]

19. Poon, H.; Chang, M.H.; Fung, H.B. Ceftaroline fosamil: A cephalosporin with activity against methicillin-resistant Staphylococcus aureus. Clin. Ther. 2012, 34, 743-765. [CrossRef]

20. File, T.M., Jr.; Low, D.E.; Eckburg, P.B.; Talbot, G.H.; Friedland, H.D.; Lee, J.; Llorens, L.; Critchley, I.A.; Thye, D.A.; Pullman, J.; et al. FOCUS 1: A randomized, double-blinded, multicentre, Phase III trial of the efficacy and safety of ceftaroline fosamil versus ceftriaxone in community-acquired pneumonia. J. Antimicrob. Chemother. 2011, 66 (Suppl. 3), iii19-32. [CrossRef]

21. Low, D.E.; File, T.M., Jr.; Eckburg, P.B.; Talbot, G.H.; David Friedland, H.; Lee, J.; Llorens, L.; Critchley, I.A.; Thye, D.A.; Corral, J.; et al. FOCUS 2: A randomized, double-blinded, multicentre, Phase III trial of the efficacy and safety of ceftaroline fosamil versus ceftriaxone in community-acquired pneumonia. J. Antimicrob. Chemother. 2011, 66 (Suppl. 3), iii33-44. [CrossRef] [PubMed]

22. Zhong, N.S.; Sun, T.; Zhuo, C.; D’Souza, G.; Lee, S.H.; Lan, N.H.; Chiang, C.-H.; Wilson, D.; Sun, F.; Iaconis, J.; et al. Ceftaroline fosamil versus ceftriaxone for the treatment of Asian patients with community-acquired pneumonia: A randomised, controlled, double-blind, phase 3, non-inferiority with nested superiority trial. Lancet Infect. Dis. 2015, 15, 161-171. [CrossRef]

23. Cannavino, C.R.; Nemeth, A.; Korczowski, B.; Bradley, J.S.; O’Neal, T.; Jandourek, A.; Friedland, H.D.; Kaplan, S.L. A Randomized, Prospective Study of Pediatric Patients with Community-acquired Pneumonia Treated with Ceftaroline Versus Ceftriaxone. Pediatr. Infect. Dis. J. 2016, 35, 752-759. [CrossRef] [PubMed]

24. Blumer, J.L.; Ghonghadze, T.; Cannavino, C.; O’Neal, T.; Jandourek, A.; Friedland, H.D.; Bradley, J. A Multicenter, Randomized, Observer-blinded, Active-controlled Study Evaluating the Safety and Effectiveness of Ceftaroline Compared with Ceftriaxone Plus Vancomycin in Pediatric Patients With Complicated Community-acquired Bacterial Pneumonia. Pediatr. Infect. Dis. J. 2016, 35, 760-766. [CrossRef] [PubMed]

25. Higgins, J.P.; Altman, D.G.; Gotzsche, P.C.; Juni, P.; Moher, D.; Oxman, A.D.; Savović, J.; Schulz, K.F.; Weeks, L.; Sterne, J.A.C.; et al. The Cochrane Collaboration's tool for assessing risk of bias in randomised trials. BMJ 2011, 343, d5928. [CrossRef] [PubMed]

26. Fine, M.J.; Auble, T.E.; Yealy, D.M.; Hanusa, B.H.; Weissfeld, L.A.; Singer, D.E.; Coley, C.M.; Marrie, T.J.; Kapoor, W.N. A prediction rule to identify low-risk patients with community-acquired pneumonia. N. Engl. J. Med. 1997, 336, 243-250. [CrossRef] [PubMed]

27. Rhedin, S.; Lindstrand, A.; Hjelmgren, A.; Ryd-Rinder, M.; Öhrmalm, L.; Tolfvenstam, T.; Örtqvist, Å.; Rotzén-Östlund, M.; Zweygberg-Wirgart, B.; Henriques-Normark, B.; et al. Respiratory viruses associated with community-acquired pneumonia in children: Matched case-control study. Thorax 2015, 70, 847-853. [CrossRef]

28. Sotgiu, G.; Aliberti, S.; Gramegna, A.; Mantero, M.; Di Pasquale, M.; Trogu, F.; Saderi, L.; Blasi, F. Efficacy and effectiveness of Ceftaroline Fosamil in patients with pneumonia: A systematic review and meta-analysis. Respir. Res. 2018, 19, 205. [CrossRef]

(C) 2019 by the authors. Licensee MDPI, Basel, Switzerland. This article is an open access article distributed under the terms and conditions of the Creative Commons Attribution (CC BY) license (http://creativecommons.org/licenses/by/4.0/). 